\title{
Phlebotomine Sand Flies in Porteirinha, an Area of American Visceral Leishmaniasis Transmission in the State of Minas Gerais, Brazil
}

\author{
Ricardo Andrade Barata, João Carlos França da Silva*, Roberto Teodoro da Costa*, \\ Consuelo Latorre Fortes-Dias**, Jaime Costa da Silva***, Edvá Vieira de Paula***, \\ Aluízio Prata****, Érika Míchalsky Monteiro, Edelberto Santos D ias/ ${ }^{+}$
}

Centro de Pesquisas René Rachou-Fiocruz, Av. Augusto de Lima 1715, 30190-002 Belo Horizonte, MG, Brasil *Universidade Federal de Minas Gerais, Belo Horizonte, MG, Brasil **Fundação Ezequiel Dias, Belo Horizonte, MG, Brasil ***Fundação

Nacional de Saúde, Belo Horizonte, MG, Brasil ****Faculdade de Medicina do Triângulo Mineiro, Uberaba, MG, Brasil

A study of the phlebotomine sand fly fauna was carried out in an endemic area of American visceral leishmaniasis (AVL) in the municipality of Porteirinha, in the Brazilian state of Minas Gerais. Captures were performed with CDC light traps in 7 districts, 5 days per month, during 2 consecutive years (January 2000 to December 2001). A total of 3240 sand flies were captured and identified. Sixteen species were found, among which 15 belonged to the genus Lutzomyia and one to the genus Brumptomyia. Lutzomyia longipalpis, a proven vector of AVL, was the predominant species (71.85\%) throughout the time period. The interference of climatic factors (temperature, humidity, and rainfall) over the populational dynamics of the sand flies was determined. Statistical analysis of the data showed a significant correlation among the number of phlebotomine sand flies collected, rainfall, and humidity, whereas the effect of temperature was negligible, in that particular region. The amount of collected phlebotomine, the number of human cases, and the prevalence of canine AVL in the districts of Porteirinha are discussed.

Key words: Phlebotominae - Lutzomyia longipalpis - American visceral leishmaniasis - Porteirinha - Minas Gerais - Brazil

Leishmaniases are zoonoses of great importance in human and veterinary medicine, caused by Leishmania parasites (Kinetoplastida: Trypanosomatidae). The transmission occurs by biting of infected females of phlebotomine sand flies (Diptera: Psychodidae: Phlebotominae) from the genus Phlebotomus and Lutzomyia, in the Old and New World, respectively.

In Brazil, a visceral form of leishmaniasis, known as American visceral leishmaniasis (AVL), is spread throughout the country, with a significant number of reported cases in 4 of its 5 geographical regions. The causative agent of AVL is Leishmania (Leishmania) chagasi. There is a proposition that L. infantum and L. chagasi may be a single species, due to the presence of common characteristics (Lainson \& Shaw 1987).

Over the last 10 years, endemic regions have been spreading further afield and there has been a sharp increase in the number of recorded cases of the disease (WHO 2001). A condition that has contributed to the observed urbanization of AVL has been the progressive adaptation of sylvatic phlebotomine to environmental modifications caused by man, associated with a constant migra-

Financial support: Fundação Nacional de Saúde, Centro de Pesquisas René Rachou, Faculdade de Medicina do Triângulo Mineiro, Universidade Federal de Minas Gerais

+Corresponding author. Fax:+ 55- 31- 3295.3566. E-mail: edel@cpqrr.fiocruz.br

Received 2 March 2004

Accepted 19 July 2004 tion of rural populations to suburban areas (Marzochi 1989, Bejarano et al. 2002).

The epidemiological chain of AVL includes the concomitant presence of the vector, a reservoir and a susceptible host in the same area (Almeida-Silva 2002). In human dwellings, an important role is played by dogs, that act as reservoirs for the parasite (Deane \& Deane 1962, Quinnell et al. 1997). The vectorial ability is restricted to certain phlebotomine sand fly species and L. longipalpis is the main vector of human and canine AVL (Grimaldi et al. 1989, Dedet 1993). More recent studies have incriminated 2 other species, L. evansi (Nuñez-Tovar 1924) and L. cruzi (Mangabeira 1938) in Colombia and Brazil, respectively (Travi et al. 1990, 1996, Galati et al. 1997).

Considering the importance of the vector in the tripod that sustains AVL transmission, the occurrence of active transmission in the municipality and the poor knowledge of the local fauna of phlebotomine, we decided to undertake an entomological survey in the municipality of Porteirinha, state of Minas Gerais, Brazil. The interference of climatic conditions in the dynamics of the phlebotomine population and any possible association between the presence of the vector and incidence data of AVL were also investigated.

\section{MATERIALS AND METHODS}

Study area - The municipality of Porteirinha (15 $44^{\prime} 42^{\prime \prime}$ $\left.\mathrm{S}, 43^{\circ} 01^{\prime} 46^{\prime \prime} \mathrm{W}\right)$ is located in the northern part of the state of Minas Gerais, in a region known as the "Dry Polygon". It occupies an area of $1787 \mathrm{~km}^{2}$ with a mean altitude of $567 \mathrm{~m}$ (IBGE 1997). The climate is tropical semi-humid (average temperatures of $24^{\circ} \mathrm{C}$ ), with a dry season of about 6 months per year. In the last few years, the region has been 
submitted to prolonged dry seasons that increased the emigration index. According to the Brazilian National Health Foundation (Funasa 2002) the local population consists of 35,465 inhabitants, $41 \%$ of whom are in the urban area. The great majority of domiciles lack basic sanitary conditions and the close presence of domestic animals is a notable characteristic.

Capture sites - Porteirinha municipality was divided into 7 regions (districts), with 2 capture sites per district (Fig. 1). Comparable sites were chosen taking into account the occurrence of human cases of leishmaniases and/or the presence of dogs with positive serology for calazar. The same sites were used repeatedly for the trapping of sand flies.

Phlebotomine captures - Sand flies were captured at night with CDC light traps (Sudia \& Chamberlain 1962) which were systematically mounted at 18:00 $\mathrm{h}$ and taken down at 08:00 $\mathrm{h}$ the next day, for 5 consecutive days in the last week of each month, from January 2000 to December 2001. Unfortunately, no captures could be performed in January and February of 2001 due to technical problems. The captured specimens were preserved in glass vials containing $70 \%$ ethanol and transferred to the laboratory.

Phlebotomine identification - The taxonomic keys of Young and Duncan (1994) and Martins et al. (1978) were used for identification of the sand fly species. Specimens with missing or damaged characters that impaired the identification at the specific level were considered as Lutzomyia spp.
Climate data - The daily climate data were kindly provided by the Janaúba Section of the Empresa de Pesquisas Agropecuárias de Minas Gerais (Epamig). Average monthly values were used in our study.

Statistical analysis - The interference of climate factors (temperature, humidity, and rainfall), as independent variables, over the number of phlebotomine sand flies captured (dependent variable) was evaluated by best subsets and backward stepwise regressions using the SigmaStat software (Jandel 1995) with $\mathrm{P} \leq 0.05$.

\section{RESULTS}

After 22 months and $1540 \mathrm{~h}$ of field capture, $1131 \mathrm{fe}$ males (34.91\%) and 2109 males (65.09\%) were collected in a total of 3240 phlebotomine specimens. The distribution of species per month and sex is shown in Table I, as well as the percentual distribution of each, considering both sexes. The following species were captured: Brumptomyia avellari (Costa Lima 1932), L. capixaba Dias, Falcão, Silva \& Martins 1987, L. cavernicola (Costa Lima 1932), L. intermedia (Lutz \& Neiva 1912), L. ischnacantha Martins, Souza \& Falcão 1962, L. lenti (Mangabeira 1938), L. longipalpis (Lutz \& Neiva 1912), L. migonei (França 1920), L. peresi (Mangabeira 1942), L. quinquefer (Dyar 1929), L. renei (Martins, Falcão \& Silva 1957), L. sallesi (Galvão \& Coutinho 1939), L. sordellii (Shannon \& Del Ponte 1927), L. termitophila Martins, Falcão \& Silva 1964, L. trinidadensis (Newstead 1922), and L. whitmani (Antunes \& Coutinho 1939). L. longipalpis was the predominant

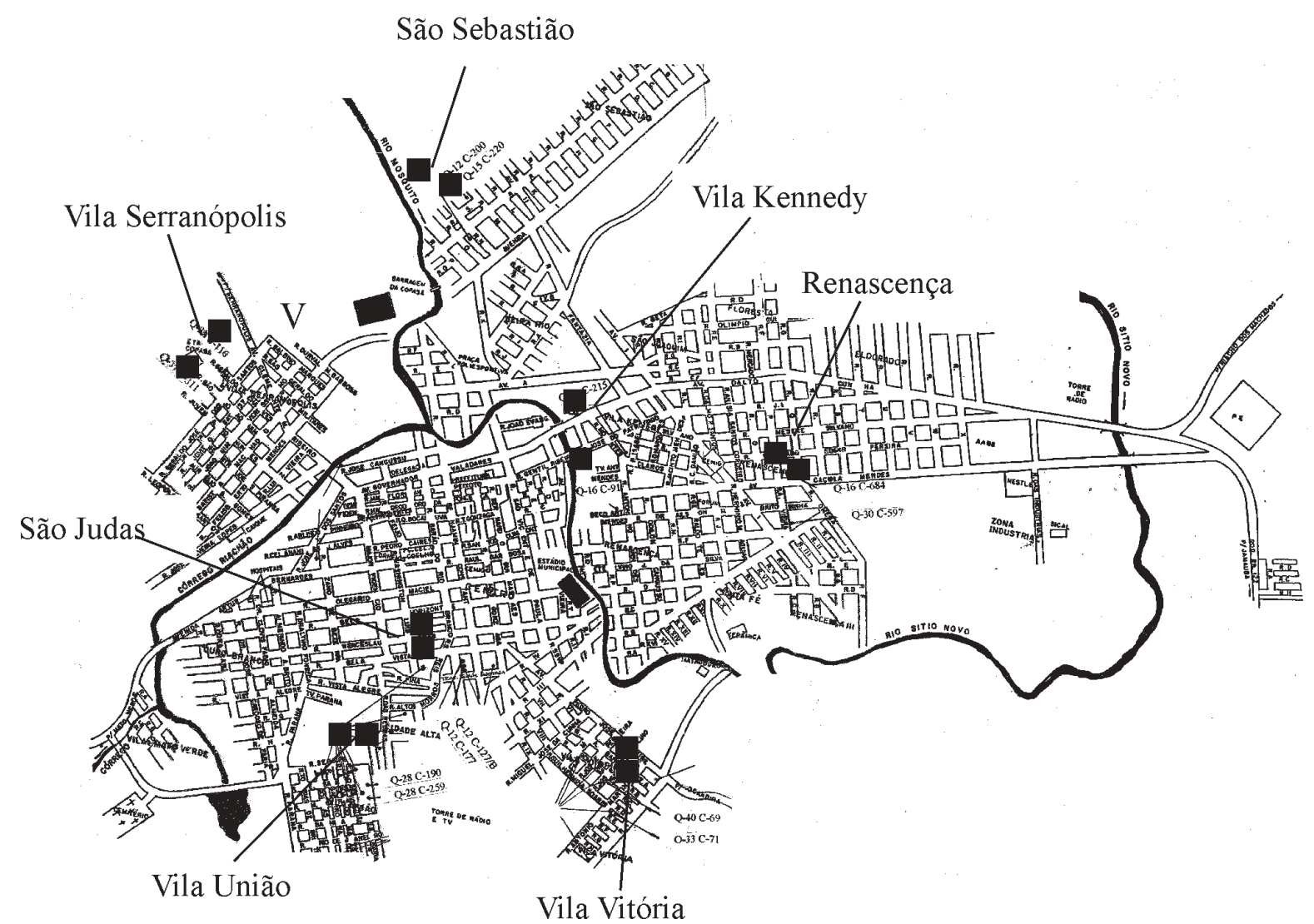

Fig. 1: map of Porteirinha, state of Minas Gerais (Brazil) with identification of its districts and localization of the sites of phlebotomine captures $(\mathbf{\square})$ 


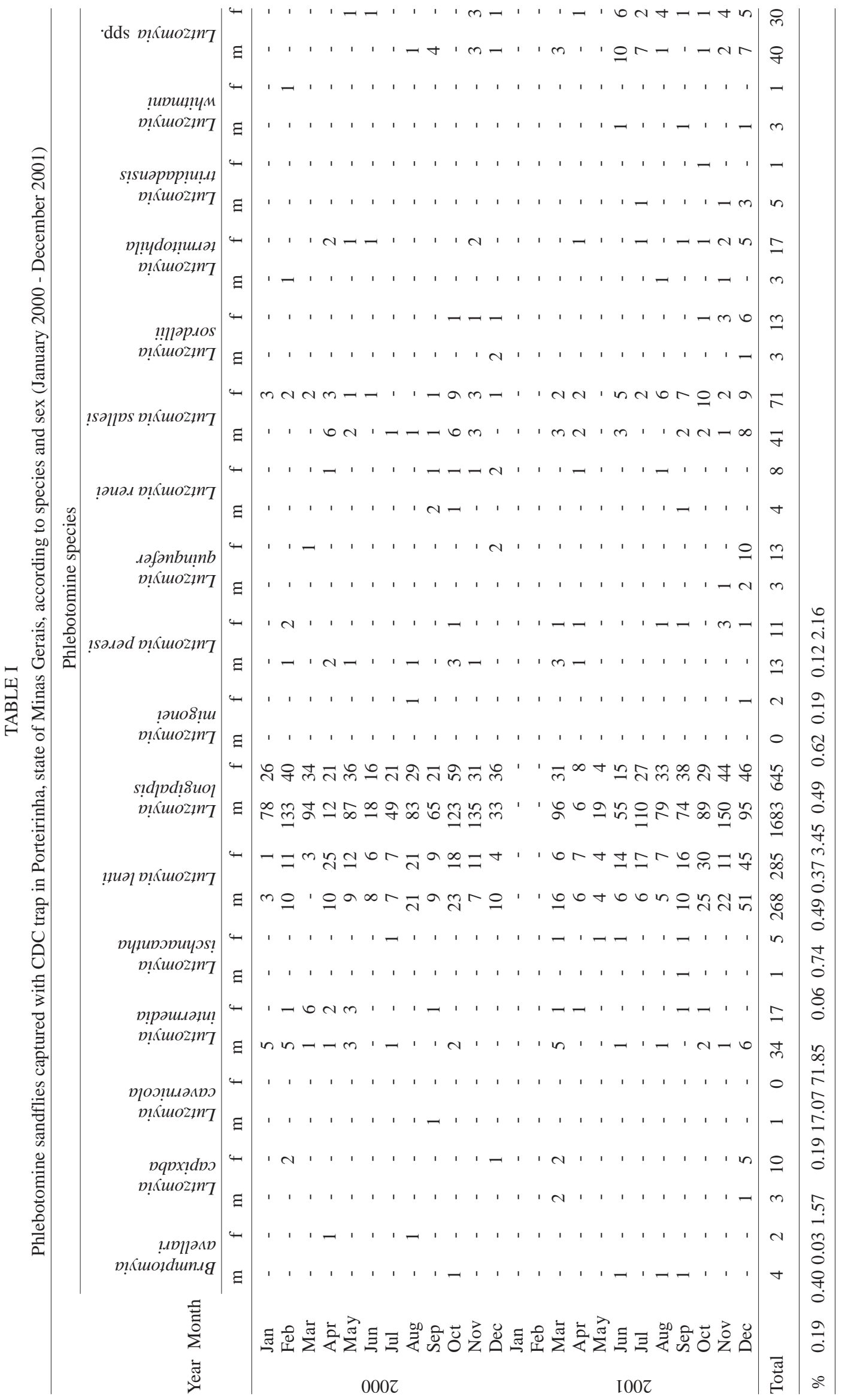


species performing $71.85 \%$ of the total of phlebotomine sand flies captured.

Monthly distribution of species per sex and per district of capture is depicted in Table II. The highest numbers of specimens were collected at the districts of São Judas (1249), Vila União (700), and Renascença (639). The male to female ratio was roughly $2: 1$ in most districts.

In a preliminary analysis by best subsets regression of the 3 main climatic factors over the number captured specimens (Table III), rainfall was the most significant variable (data not shown). Further analysis by backward stepwise regression demonstrated that the relative humidity was also important (Fig 2.). Based on the experimental data, the relationship between the number of phlebotomine collected and the 2 interfering climatic variables (rainfall and humidity) could be represented by the mathematical equation

$$
\mathrm{A}=438.784+0.954 \mathrm{~B}-6.434 \mathrm{C}
$$

where $\mathrm{A}$ is the number of phlebotomine sand flies collected, $\mathrm{B}$ is the average monthly rainfall index, and $\mathrm{C}$ is the average monthly relative humidity. The multiple correlation coefficient $(\mathrm{R})$ calculated for this equation was 0.687 , that means a good adequacy of the mathematical model to the experimental data. The effect of the third climatic variable available (temperature) was negligible, not adding significantly to the ability of the equation to predict the number of phlebotomine sand flies collected. Therefore, this variable was not included in the model.

The mathematical equation was applied to the present study in order to predict the number of phlebotomine that one might expected to have collected in January and February of 2001 (missing data), based on the climatic conditions of each month. The estimated numbers of phlebotomine would be 133 and 113 for January and February, respectively. These theoretical data were represented in Fig. 2, to allow a comparison with the experimental data.

The number and percentage of phlebotomine collected per region is listed in Table IV, as well as the human cases and the prevalence of canine AVL in the period of the study (França-Silva 2003). The majority of human cases, 10 and 4 respectively, were reported in Vila União and São Judas, where the prevalence of canine AVL is high and a significant percentages of sand flies $(21.61 \%$ and $38.54 \%$ respectively) were captured. Such a coincidence was not observed in the district of Renascença, where a high proportion of sand flies was observed but no human cases were notified.

\section{DISCUSSION}

Descriptions of phlebotomine fauna and studies on the behaviour of some phlebotomine species have been the subject of several investigations (Andrade-Filho et al. 1997, Mayo et al. 1998, Rebêlo et al. 2001). These in-

TABLE II

Distribution of phlebotomine specimens collected per district, sex, and month, in the municipality of Porteirinha, state of Minas Gerais, between January 2000 and December 2001

\begin{tabular}{|c|c|c|c|c|c|c|c|c|c|c|c|c|c|c|c|}
\hline \multirow{3}{*}{ Year } & \multirow{3}{*}{ Month } & \multicolumn{14}{|c|}{ District } \\
\hline & & \multicolumn{2}{|c|}{ Renascença } & \multicolumn{2}{|c|}{ São Judas } & \multicolumn{2}{|c|}{ São Sebastião } & \multicolumn{2}{|c|}{ Vila Kennedy } & \multicolumn{2}{|c|}{ Vila Serranópolis } & \multicolumn{2}{|c|}{ Vila União } & \multicolumn{2}{|c|}{ Vila Vitória } \\
\hline & & $\mathrm{m}$ & f & $\mathrm{m}$ & f & $\mathrm{m}$ & $\mathrm{f}$ & $\mathrm{m}$ & f & $\mathrm{m}$ & f & $\mathrm{m}$ & $\mathrm{f}$ & $\mathrm{m}$ & $\mathrm{f}$ \\
\hline \multirow[t]{12}{*}{2000} & Jan & 13 & 3 & 68 & 16 & 2 & 2 & 0 & 0 & 0 & 0 & 4 & 7 & 0 & 2 \\
\hline & Feb & 12 & 3 & 115 & 35 & 1 & 3 & 1 & 0 & 10 & 9 & 10 & 7 & 2 & 2 \\
\hline & Mar & 3 & 7 & 90 & 34 & 0 & 0 & 0 & 0 & 0 & 2 & 2 & 1 & 0 & 2 \\
\hline & Apr & 1 & 5 & 23 & 21 & 0 & 2 & 0 & 0 & 0 & 3 & 6 & 16 & 1 & 8 \\
\hline & May & 21 & 14 & 26 & 17 & 10 & 6 & 6 & 0 & 0 & 0 & 36 & 13 & 3 & 4 \\
\hline & Jun & 7 & 6 & 5 & 2 & 0 & 3 & 1 & 5 & 0 & 0 & 11 & 9 & 2 & 0 \\
\hline & Jul & 29 & 8 & 9 & 12 & 6 & 0 & 2 & 0 & 1 & 0 & 7 & 7 & 4 & 2 \\
\hline & Aug & 25 & 11 & 20 & 19 & 9 & 4 & 3 & 2 & 2 & 2 & 41 & 7 & 7 & 7 \\
\hline & Sep & 47 & 15 & 15 & 4 & 4 & 1 & 4 & 0 & 1 & 3 & 7 & 5 & 4 & 5 \\
\hline & Oct & 65 & 27 & 50 & 30 & 14 & 3 & 6 & 5 & 5 & 4 & 15 & 14 & 4 & 6 \\
\hline & Nov & 27 & 13 & 104 & 30 & 1 & 2 & 1 & 1 & 1 & 0 & 8 & 2 & 7 & 4 \\
\hline & Dec & 2 & 0 & 37 & 33 & 0 & 0 & 0 & 0 & 0 & 3 & 4 & 8 & 3 & 4 \\
\hline \multirow[t]{12}{*}{2001} & Jan & - & - & - & - & - & - & - & - & - & - & - & - & - & - \\
\hline & Feb & - & - & - & - & - & - & - & - & - & - & - & - & - & - \\
\hline & Mar & 92 & 24 & 12 & 5 & 2 & 2 & 3 & 1 & 6 & 3 & 5 & 6 & 9 & 3 \\
\hline & Apr & 2 & 3 & 4 & 4 & 0 & 3 & 0 & 0 & 1 & 1 & 6 & 6 & 2 & 3 \\
\hline & May & 4 & 2 & 4 & 1 & 3 & 1 & 1 & 0 & 0 & 0 & 11 & 2 & 0 & 3 \\
\hline & Jun & 4 & 5 & 12 & 8 & 4 & 1 & 1 & 0 & 3 & 3 & 43 & 16 & 10 & 8 \\
\hline & Jul & 2 & 2 & 27 & 10 & 5 & 5 & 0 & 1 & 9 & 6 & 74 & 15 & 7 & 10 \\
\hline & Aug & 10 & 15 & 22 & 7 & 6 & 3 & 1 & 3 & 2 & 2 & 43 & 18 & 4 & 4 \\
\hline & Sep & 19 & 13 & 17 & 11 & 4 & 6 & 1 & 0 & 5 & 5 & 35 & 23 & 9 & 8 \\
\hline & Oct & 16 & 12 & 36 & 34 & 7 & 1 & 2 & 6 & 7 & 16 & 46 & 2 & 5 & 3 \\
\hline & Nov & 5 & 4 & 74 & 23 & 2 & 2 & 2 & 0 & 70 & 14 & 19 & 23 & 6 & 3 \\
\hline & Dec & 32 & 8 & 76 & 47 & 19 & 7 & 0 & 2 & 13 & 25 & 29 & 31 & 6 & 12 \\
\hline Total & & 438 & 201 & 846 & 403 & 99 & 57 & 35 & 26 & 136 & 101 & 462 & 238 & 95 & 103 \\
\hline
\end{tabular}

m: male; f: female 
TABLE III

Climatic conditions in Porteirinha, state of Minas Gerais, between January 2000 and December 2001

\begin{tabular}{|c|c|c|c|}
\hline Month & $\begin{array}{c}\text { Average } \\
\text { temperature } \\
{ }^{\circ} \mathrm{C}\end{array}$ & $\begin{array}{c}\text { Relative } \\
\text { humidity } \\
\%\end{array}$ & $\begin{array}{c}\text { Rainfall } \\
\mathrm{mm}\end{array}$ \\
\hline 1 & 25.1 & 73.0 & 224.3 \\
\hline 2 & 26.0 & 65.1 & 120.0 \\
\hline 3 & 25.9 & 65.7 & 111.6 \\
\hline 4 & 25.5 & 57.4 & 0.2 \\
\hline 5 & 24.1 & 52.3 & 0 \\
\hline 6 & 23.0 & 48.1 & 0 \\
\hline 7 & 22.8 & 49.3 & 0 \\
\hline 8 & 24.0 & 43.7 & 0 \\
\hline 9 & 24.9 & 47.7 & 11.1 \\
\hline 10 & 27.4 & 40.7 & 52.8 \\
\hline 11 & 26.0 & 63.7 & 129.5 \\
\hline 12 & 25.4 & 77.0 & 248.7 \\
\hline 13 & 25.7 & 60.7 & 89.1 \\
\hline 14 & 27.2 & 53.6 & 19.8 \\
\hline 15 & 26.2 & 64.0 & 87.8 \\
\hline 16 & 26.3 & 52.0 & 8.6 \\
\hline 17 & 25.9 & 54.0 & 15.6 \\
\hline 18 & 23.7 & 51.5 & 0 \\
\hline 19 & 23.2 & 50.0 & 0 \\
\hline 20 & 24.0 & 44.3 & 0 \\
\hline 21 & 26.1 & 43.4 & 4.1 \\
\hline 22 & 26.4 & 54.5 & 51.2 \\
\hline 23 & 25.8 & 67.2 & 245.1 \\
\hline 24 & 26.0 & 64.8 & 258.5 \\
\hline
\end{tabular}

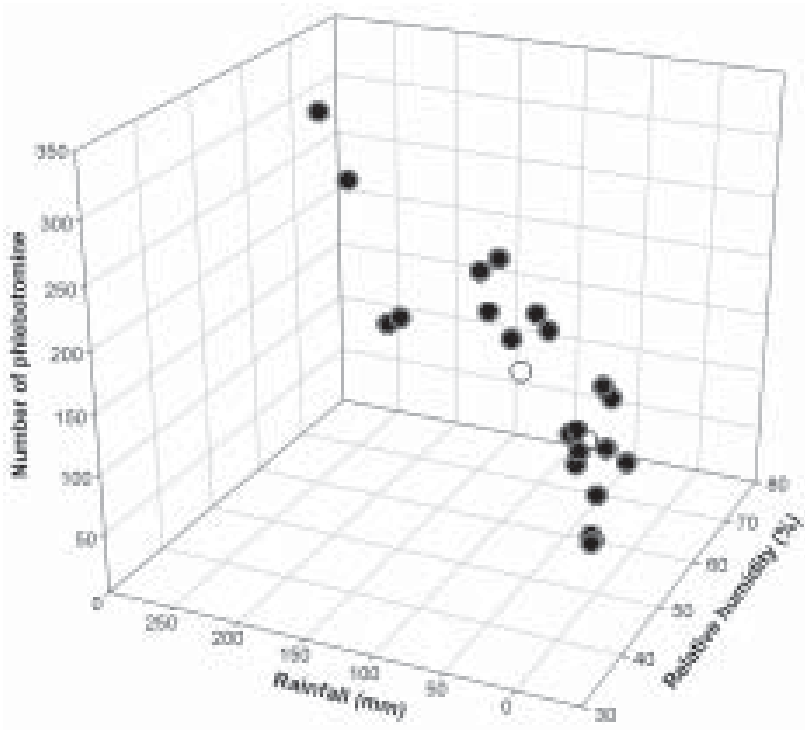

Fig. 2: dispersion plot (XYZ) of the number of phlebotomine collected as a function of the interfering climatic data (rainfall and humidity) in Porteirinha, state of Minas Gerais, Brazil. The experimental points are represented by circles filled in black. The correlation between the three variables was represented by the equation $\mathrm{A}=438.784+0.954 \mathrm{~B}-6.434 \mathrm{C}$, where $\mathrm{A}$ is the number of phlebotomine sand flies collected, B is the rainfall index, and $\mathrm{C}$ is the relative humidity. A multiple correlation coefficient $(\mathrm{R})$ of 0.687 was found for this model. The two white circles represent the predicted number of phlebotomine that would be expected to be collected in Porteirinha in the two months lacking these data (January and February of 2001).

\section{TABLE IV}

Number of phlebotomine sand flies collected, human cases of American visceral leishmaniasis (AVL), and prevalence of canine AVL per district in Porteirinha, state of Minas Gerais

\begin{tabular}{|c|c|c|c|c|}
\hline \multirow[b]{2}{*}{ District } & \multicolumn{2}{|c|}{ Phlebotomine } & \multirow{2}{*}{$\begin{array}{l}\text { Human cases } \\
\text { of } \mathrm{AVL}^{a}\end{array}$} & \multirow{2}{*}{$\begin{array}{c}\text { Prevalence of } \\
\text { canine AVL } b(\%)\end{array}$} \\
\hline & Number & $\%$ & & \\
\hline Renascença & 639 & 19.72 & 0 & 1.17 \\
\hline São Judas & 1249 & 38.54 & 4 & 1.28 \\
\hline São Sebastião & 156 & 4.81 & 0 & 1.31 \\
\hline Vila Kennedy & 61 & 1.89 & 0 & 0.75 \\
\hline Vila Serranópolis & 237 & 7.31 & 2 & 0.50 \\
\hline Vila União & 700 & 21.61 & 10 & 1.55 \\
\hline Vila Vitória & 198 & 6.12 & 2 & 0.99 \\
\hline Total & 3240 & 100.00 & 18 & - \\
\hline
\end{tabular}

$a$ : reported cases; $b$ : average prevalence from January 2000 to December 2001 (França-Silva 2003)

sects are found frequently in natural ecotopes such as tree trunks, animal burrows, dead leaves, rock clefts (Aguiar et al. 1985, Alexander et al. 1992, Azevedo et al. 1993) as well as in rural and urban environments nearby domestic animal shelters and human houses.

Although in the beginning AVL was a sylvatic disease, characteristic of rural environments, its expansion and urbanization was long foreseen (Deane \& Deane 1956). As the main causes we have the environmental modifications by man such as deafforestation, reduction in the number of sylvatic animals and providing humans and domestic dogs as alternative feeding sources for the vector, plus the migration of people from endemic rural areas to city peripheries (Funasa 2002). Recent data confirm the urbanization of AVL in cities of median and great sizes in Brazil (Monteiro et al. 1994, Silva et al. 2001). According to Marzochi and Marzochi (1994) and to Santa Rosa (1997) the main condition for transmission in these new environments is the adaptation of the vectors. This adaptation process seems to be ongoing in Porteirinha, where the highest frequency of phlebotomine occurred in those districts that have been devastated, forming islands 
of isolated vegetation (capons) and where the houses are placed, in most cases, in the confluence of downward slopes of mountains (gulfs). These areas are represented by the districts of São Judas, Vila União $(21.61 \%)$, and Renascença, where the phlebotomine sand flies are present in high numbers, performing $38.54 \%, 21.61 \%$, and $19.72 \%$ of the total number of specimens captured (Table IV).

The higher proportion of males in the captures with CDC traps could be explained by a natural behaviour, in which the males follow the females to assure fertilization during their displacements. Similar data were observed by Domingos et al. (1998) for L. intermedia. The interference of climatic factors on phlebotomine populations has been studied before by other authors. Feliciangeli (1987) demonstrated that rainfall levels and the consequent relative humidity were the most important variables in the seasonality of some species of phlebotomine in an endemic focus of cutaneous leishmaniasis in Venezuela. On the other side, the combination of temperature and humidity influenced strongly the population of phlebotomine in various habitats in the Panama Canal zone (Rutledge \& Ellenwood 1975). In Porteirinha, the temperature did not show a major effect, probable because of its maintenance between $23^{\circ}$ and $28^{\circ} \mathrm{C}$ throughout the two-year period, with no drastic variations. The rainfall and the humidity, however, were decisive in the populational dynamics of the sand flies. The correlation between the number of sand flies captured and these two variables was expressed by a mathematical model, supported by a significant correlation coefficient (Fig. 2). This model was successfully tested here for a theoretical prediction of the expected number of sand flies in two months of the study where no captures could be performed. The availability of such a model in a given area could be advantageous in Public Health. For instance, a comparison between the expected population, based on a previously determined model for a given area, versus the actual population under known climatic conditions, could be useful to evaluate the effectiveness of health measures.

The presence of L. longipalpis in high numbers, as observed over the two-year period of our study, assures the presence of the vector and the maintenance of the local transmission of AVL in Porteirinha, where reservoirs (dogs) and hosts (humans) are also present.

\section{ACKNOWLEDGEMENTS}

To the agents of the Brazilian National Foundation of Health (Funasa) Jeová Vitor dos Santos, Saulo Neres de Almeida, and Amilton Ferreira Damasceno, for their friendship and technical help in the field trips. To the people from Porteirinha for their collaboration during the study.

\section{REFERENCES}

Aguiar GM, Schuback PA, Vilela ML, Azevedo ACR 1985. Aspectos da ecologia dos flebótomos do Parque Nacional da Serra dos Órgãos, Rio de Janeiro. II - Distribuição vertical (Diptera, Psychodidae, Phlebotominae). Mem Inst Oswaldo Cruz 80: 187-194.

Alexander B, Ferro C, Young DG, Morales A, Tesh RB 1992. Ecology of phlebotomine sand flies (Diptera: Psychodidae) in a focus of Leishmania (Viannia) braziliensis in Northern Colombia. Mem Inst Oswaldo Cruz 87: 387-395.
Almeida-Silva L 2002. Estudo Prospectivo de Indivíduos com Testes Imunológicos e Reação em Cadeia da Polimerase para Calazar em Porteirinha, Minas Gerais, Brasil, MSc Thesis, Faculdade de Medicina do Triângulo Mineiro, Uberaba.

Andrade-Filho JD, Carneiro APS, Lima MLN, Santiago RM, Gama MA, Santos CA, Falcão AL, Brazil RP 1997. Flebotomíneos de Timóteo, Estado de Minas Gerais, Brasil (Diptera: Psychodidae). Cad Saúde Pública 13: 767-770.

Azevedo ACR, Luz SLB, Vilela ML, Rangel EF 1993. Studies on the sandfly fauna of Samuel ecological station, Porto Velho municipality, Rondônia state, Brazil. Mem Inst Oswaldo Cruz 88: 509-512.

Bejarano EE, Uribe S, Rojas W, Vélez ID 2002. Phlebotomine sand flies (Diptera:Psychodidae) associated with the appearance of urban leishmaniasis in the city of Sincelejo, Colombia. Mem Inst Oswaldo Cruz 97: 645-647.

Deane LM, Deane MP 1956. Leishmaniose visceral urbana (no cão e no homem) em Sobral, Ceará. O Hospital 47: 75-87.

Deane LM, Deane MP 1962. Visceral leishmaniasis in Brazil. Geographical distribution and transmission. Rev Inst Med Trop São Paulo 4: 149-212.

Dedet JP 1993. Leishmania et leishmaniose du Continent américan. Ann Inst Pasteur 4: 3-26.

Domingos MF, Carreri-Bruno GC, Ciaravolo RMC, Galati EAB, Wanderley DMV, Corrêa FMA 1998. Leishmaniose tegumentar americana: flebotomíneos de área de transmissão, no município de Pedro de Toledo, região sul do estado de São Paulo, Brasil. Rev Soc Bras Med Trop 31: 425-432.

Feliciangeli MD 1987. Ecology of sandflies (Diptera: Psychodidae) in a restricted focus of cutaneous leishmaniasis in Northern Venezuela. III - Seasonal fluctuation. Mem Inst Oswaldo Cruz 82: 167-176.

França-Silva JC 2003. Distribuição Espacial e Temporal da Leishmaniose Visceral Canina em Relação à Densidade Vetorial e ao Controle de Cães Infectados em PorteirinhaMinas Gerais (1998-2002), PhD Thesis, Universidade Federal de Minas Gerais, Belo Horizonte.

Funasa 2002. Leishmaniose visceral no Brasil: situação atual, principais aspectos epidemiológicos, clínicos e medidas de controle. Boletim eletrônico epidemiológico 6.

Galati EAB, Nunes VLB, Rego-Jr FA, Oshiro ET, Chang MR 1997. Estudo de flebotomíneos (Diptera: Psychodidae) em foco de leishmaniose visceral no Estado de Mato Grosso do Sul, Brasil. Rev Saúde Pública 31: 378-390.

Grimaldi Jr G, Tesh RB, Pratt DM 1989. A review of geographical distribution and epidemiology of leishmaniasis in the New World. Am J Trop Med Hyg 41: 687-725.

IBGE-Instituto Brasileiro de Geografia e Estatística 1997. Anuário Estatístico do Brasil.

Jandel B 1995. SigmaStat statistical user's manual, version 2.0. Jandel, San Rafael, CA.

Lainson R, Shaw JJ 1987. Evolution, classification and geographical distribution. In W Peters, R Killick-Kendrick (eds), The Leishmaniasis in Biology and Medicine, Academic Press, London, p. 1-20.

Martins AVP, Williams P, Falcão AL 1978. American Sand Flies (Diptera, Psychodidae, Phlebotominae), Academia Brasileira de Ciências, Rio de Janeiro, 195 pp.

Marzochi MCA 1989. A leishmaniose tegumentar no Brasil. In Grandes Endemias Brasileiras, Universidade de Brasília, Brasília.

Marzochi MCA, Marzochi KBF 1994. Tegumentary and visceral leishmaniases in Brazil - Emerging anthropozoonosis and possibilites for their control. Cad Saúde Pública 10: 359-375. 
Mayo RC, Casanova C, Mascarini LM, Pignatti MG, Rangel O, Galati EAB, Warderley DMV, Corrêa FMA. 1998. Flebotomíneos (Diptera, Psychodidae) de área de transmissão de leishmaniose tegumentar americana, no município de Itupeva, região sudeste do Estado de São Paulo. Rev Soc Bras Med Trop 31: 339-345.

Monteiro SP, Lacerda MM, Arias JR 1994. Controle da leishmaniose visceral no Brasil. Rev Soc Bras Med Trop 27: 67-72.

Quinnell RJ, Courtenay O, Garcez L, Dye C 1997. The epidemiology of canine leishmaniasis: transmission rates estimated from a cohort study in Amazonian Brazil. Parasitology 115: 143-156.

Rebêlo JMM, Oliveira ST, de Silva FS, Barros VLL, Costa JML 2001. Sandflies (Diptera: Psychodidae) of the Amazônia of Maranhão. V. Seasonal ocurrence in ancient colonization area and endemic for cutaneous leishmaniasis. Rev Bras Biol 61: 107-15.

Rutledge LC, Ellenwood DA 1975. Production of phlebotomine sandflies on the open forest floor on Panama: the species complement. Environ Ent 4: 71-77.

Santa Rosa ICA 1997. Perfil Epidemiológico dos Casos de Leishmaniose Tegumentar Americana Notificados na Região
Metropolitana de Belo Horizonte, Minas Gerais, 1989 a 1995, MSc Thesis, Universidade Federal de Minas Gerais, Belo Horizonte.

Silva ES, Gontijo CMF, Pacheco RS, Fiuza VOP, Brazil RP 2001. Visceral leishmaniasis in the Metropolitan region of Belo Horizonte, state of Minas Gerais, Brazil. Mem Inst Oswaldo Cruz 96: 285-291.

Sudia WA, Chamberlain RW 1962. Battery-operated light trap: an improved model. Mosq News 22: 126-129.

Travi BL, Montoya J, Gallego J, Jamarillo C, Llano R, Velez ID 1996. Bionomics of Lutzomyia evansi (Diptera: Psychodidae), vector of visceral leishmaniasis in Northern Colombia. J Med Ent 33: 278-285.

Travi BL, Velez ID, Brutus L, Segura I, Jamarillo C, Montoya J 1990. Lutzomyia evansi, an alternate vector of Leishmania chagasi in a Colombian foci in the Pacific coast region. Trans $R$ Soc Trop Med Hyg 84: 676-677.

World Health Organization 2001. www.who.int/emc/diseases/ leish/leisdis1.html

Young DG, Duncan MA 1994. Guide to the identification and geographic distribution of Lutzomyia sand flies in Mexico, the West Indies, Central and South America (Diptera: Psychodidae). Mem Am Ent Inst 54: 1-881. 
